\section{Hardening is dead, long live softening; time to focus on reducing disparities in smoking}

\author{
Richard Edwards
}

The hardening hypothesis proposes that as smoking prevalence declines, the proportion of 'hard-core' or 'hardened' smokers increases. The intuitively plausible logic is that less addicted and more motivated smokers are more likely to quit, leaving behind a growing proportion of 'hardened' smokers. If true, the hypothesis has implications for policy formulation and smoking cessation practice. For example, smokefree policies, health promotion campaigns and smoking cessation support services may need to be modified to ensure they reach and support quitting among the growing proportion of hardened smokers. Also, hardening would strengthen the justification for harm reduction strategies due to the need to provide less harmful alternatives to the increasing proportion of 'hardened' smokers who struggle to quit.

There are many ways in which hardening could manifest, creating multiple hypotheses which can be tested. For example, the population of smokers could become: (1) more highly addicted (eg, an increase in heavier or more dependent smokers); (2) less motivated to quit (eg, more smokers with no or low intention to quit, not making quit attempts or with lower self-efficacy about quitting); and (3) increasingly disadvantaged and marginalised (eg, more smokers who are disadvantaged or have mental health conditions). The net effect should be a reduced rate of quitting among the smoking population over time.

So what is the evidence for hardening? Most studies that have looked at the different aspects of hardening, either singly or in combination, are repeated surveys from the same population. Investigations from a variety of countries have generally found little or no evidence in support of the hypothesis. ${ }^{1-13}$

The study reported in this edition of the journal by Brennan and colleagues adds to this (lack of) evidence through a rigorous analysis of repeated cross-sectional surveys in Victoria, Australia between 2001 and

Correspondence to Dr Richard Edwards, Public Health, University of Otago, Wellington, New Zealand; richard.edwards@otago.ac.nz
$2015 .{ }^{14}$ Strengths of the study include the long time period investigated, the wide range of hardening indicators studied, an analysis of hardening within demographic subgroups and sensitivity analyses of the findings.

Another approach is to compare indicators of hardening between populations with different levels of smoking prevalence. The hardening hypothesis would predict that lower smoking prevalence will be associated with increased proportions of 'hardened' smokers or indicators of hardening among smokers. Again, most evidence suggests otherwise. ${ }^{15} 16$ For example, a study of US States and 31 European countries at multiple time points found lower prevalence was associated with fewer mean cigarettes smoked per day and increased quit attempts within populations. ${ }^{16}$

Due to the intuitive nature of the hypothesis, negative findings of studies investigating hardening have often been viewed as surprising. ${ }^{17}$ However, this should not be the case. If groups of smokers are considered as dynamic populations, a range of determinants of the rates of inflows and outflows of smokers are apparent which could plausibly negate hardening and instead result in softening.

For example, in most settings, nearly all new smokers joining the smoker population will be young, and many will be lighter daily or social smokers, who may be more motivated to quit. Also, while heavier smokers may be less likely to leave the smoker population by quitting, they will be more likely to leave by dying or possibly through quitting in response to developing a serious illness. The interplay of these factors will influence whether the proportion of more heavily addicted and less motivated to quit smokers increases or decreases in any smoker population over time.

In addition, the smokers in a population are not fixed in their behaviours and motivations. They will be affected by tobacco control programmes such as smokefree policies, increases in tobacco taxation and standardised packaging. If these measures are effective, they will reduce the mean number of cigarettes smoked and increase motivation to quit among existing smokers, again causing softening, particularly if some interventions (eg, price increases) impact more on heavier smokers. ${ }^{2}$ For these reasons, and maybe others, softening of the smoker population as prevalence decreases and tobacco control efforts intensify is at least as plausible as hardening.

So what remains of the hardening hypothesis, and how relevant is it to tobacco control practice? Most studies investigating hardening have occurred in relatively high-income countries (HICs), often with active and comprehensive tobacco control programmes. This begs the question of whether hardening could be a feature of lower-income and middleincome countries (LMICs) or countries with less well developed tobacco control activities. This is worth investigating, as some authors have begun to do. ${ }^{18} 19$ For example, Yin et al found high levels of hardened smokers in a range of LMICs. ${ }^{18}$

Another possibility is that while hardening may not have been found in whole populations, this may mask hardening among priority subpopulations such as smokers with mental illness, low socioeconomic status (SES) and indigenous smokers. Brennan et al found mixed evidence for this. The proportion of hardcore low SES smokers and smokers with no intention to quit in the next 6 months did not decline between 2001 and 2015 in Victoria, while smokers in higher SES groups showed substantial softening in these indicators. ${ }^{14}$ However, for most other indicators, softening occurred to a similar degree across all SES groups. Unfortunately, investigation of hardening among Australia's indigenous peoples was not investigated due to small numbers included in the surveys.

Other studies have found mixed results in this regard, but most report softening with few differences by SES, ethnicity or presence of mental distress. For example, while a US study reported softening occurred among high but not low SES smokers, ${ }^{4}$ a Dutch study found similar levels of softening over time by education level. ${ }^{12}$ A New Zealand study reported little evidence for hardening, with similar findings for Māori (indigenous peoples of New Zealand) and non-Māori smokers. ${ }^{13}$ Studies from California have found similar degrees of softening among smokers with varying levels of psychological distress and from different ethnic populations. ${ }^{2021}$

Finally, while hardening may not be occurring in the form of smoker populations becoming more addicted and less motivated to quit, it could occur through 
the proportion of marginalised smokers (eg, people with mental illness, low SES, homeless, prisoners, disadvantaged minority ethnic groups and indigenous peoples) increasing over time. This seems highly plausible, though where it has been specifically investigated, it has sometimes not been found to be the case-for example, an Australian study found no evidence of increasing prevalence of disadvantage or psychological distress among smokers over a 13-year period..$^{5}$

In summary, the hardening hypothesis, as it is commonly formulated, is largely unsupported by the evidence, at least from HICs with advanced tobacco control programmes and low smoking prevalence. Rather the evidence is of softening. This was also the conclusion of a recent review of the hardening hypothesis. ${ }^{22}$ Exploring the alternative hypothesis of softening now seems a more credible line of enquiry. ${ }^{2021}$ Investigation of whether softening is also occurring in LMICs, in countries with higher smoking prevalence and less comprehensive tobacco control programmes, and in disadvantaged population subgroups should be a priority. The issue of whether marginalised people make up a growing proportion of the smoker population should be monitored and investigated. However, there is already substantial evidence of disparities in smoking prevalence for marginalised groups in many jurisdictions. This surely requires that addressing equity should be a key concern for tobacco control practitioners and that identifying and implementing pro-equity interventions is the highest priority.

Funding The authors have not declared a specific grant for this research from any funding agency in the public, commercial or not-for-profit sectors.

Competing interests None declared.

Patient consent for publication Not required.

Provenance and peer review Commissioned; internally peer reviewed.
(C) Author(s) (or their employer(s)) 2020. No commercial re-use. See rights and permissions. Published by BMJ.

\section{A) Check for updates}

To cite Edwards R. Tob Control 2020;29:250-251. Published Online First 30 May 2019

\section{Clinked}

- http://dx.doi.org/10.1136/tobaccocontrol-2019054937

Tob Control 2020;29:250-251.

doi:10.1136/tobaccocontrol-2019-055067

ORCID iD

Richard Edwards http://orcid.org/0000-0003-22649823

\section{REFERENCES}

1 Al-Delaimy WK, Pierce JP, Messer K, et al. The California tobacco control program's effect on adult smokers: (2) daily cigarette consumption levels. Tob Control 2007;16:91-5.

2 Burns DM, Major JM, Anderson CM. Changes in cross-sectional measures of cessation, numbers of cigarettes smoked per day, and time to first cigaretteCalifornia and national data. those who continue to smoke: is achieving abstinence harder and do we need to change our interventions smoking and tobacco control monograph 15. Bethesda: U.S. Department of Health and Human Services, Public Health Service, National Institutes of Health, National Cancer Institute, 2003: 101-25.

3 Celebucki C, Brawarsky P. Hardening of the target: evidence from Massachusetts. those who continue to smoke: is achieving abstinence harder and do we need to change our interventions smoking and tobacco control monograph 15. Bethesda: U.S. Department of Health and Human Services, Public Health Service, National Institutes of Health, National Cancer Institute, 2003: 127-45.

4 Clare P, Bradford D, Courtney RJ, et al. The relationship between socioeconomic status and 'hardcore' smoking over time--greater accumulation of hardened smokers in low-SES than high-SES smokers. Tob Control 2014:23:e133-8.

5 Gartner C, Scollo M, Marquart L, et al. Analysis of national data shows mixed evidence of hardening among Australian smokers. Aust N Z J Public Health 2012:36:408-14.

6 Jarvis MJ, Giovino GA, O'Connor RJ, et al. Variation in nicotine intake among US cigarette smokers during the past 25 years: evidence from NHANES surveys. Nicotine Tob Res 2014;16:1620-8.
7 Lund M, Lund KE, Kvaavik E. Hardcore smokers in Norway 1996-2009. Nicotine Tob Res 2011;13:1132-9.

8 Mathews R, Hall WD, Gartner CE. Is there evidence of 'hardening' among Australian smokers between 1997 and 2007? Analyses of the Australian National Surveys of Mental Health and Well-Being. Aust N Z J Psychiatry 2010;44:1132-6.

9 Messer K, Pierce JP, Zhu S-H, et al. The California tobacco control program's effect on adult smokers: (1) smoking cessation. Tob Control 2007;16:85-90.

10 O'Connor RJ, Giovino GA, Kozlowski LT, et al. Changes in nicotine intake and cigarette use over time in two nationally representative cross-sectional samples of smokers. Am J Epidemiol 2006;164:750-9.

11 Pierce JPet al. Prevalence of heavy smoking in California and the United States, 1965-2007. JAMA 2011;305:1106-12.

12 Bommelé J, Nagelhout GE, Kleinjan M, et al. Prevalence of hardcore smoking in the Netherlands between 2001 and 2012: a test of the hardening hypothesis. BMC Public Health 2016;16.

13 Edwards R, Tu D, Newcombe R, et al. Achieving the tobacco endgame: evidence on the hardening hypothesis from repeated cross-sectional studies in New Zealand 2008-2014. Tob Control 2017;26:399-405.

14 Brennan E, Greenhalgh E, Durkin S, et al. Hardening or softening? an observational study of changes to the prevalence of hardening indicators in Victoria, Australia, 2001-2016. Tob Control 2020;29:252-7.

15 Fernández E, Lugo A, Clancy L, et al. Smoking dependence in 18 European countries: hard to maintain the hardening hypothesis. Prev Med 2015:81:314-9.

16 Kulik MC, Glantz SA. The smoking population in the USA and EU is softening not hardening. Tob Control 2016;25:470-5.

17 Cohen JE, McDonald PW, Selby P. Softening up on the hardening hypothesis. Tob Control 2012;21:265-6.

18 Yin S, Ahluwalia I, Palipudi K, et al. Are there hardened smokers in low- and middle-income countries? Findings from the global adult tobacco survey. Tob Induc Dis 2019;17:1-10.

19 Kishore J, Jena PK, Bandyopadhyay C, et al. Hardcore smoking in three South-East Asian countries: results from the global adult tobacco survey. Asian Pac J Cancer Prev 2013;14:625-30.

20 Kulik MC, Glantz SA, Softening Among US. Softening among U.S. smokers with psychological distress: more quit attempts and lower consumption as smoking drops. American Journal of Preventive Medicine 2017; 53:810-7

21 Kulik MC, Glantz SA. Similar softening across different racial and ethnic groups of smokers in California as smoking prevalence declined. Prev Med 2019:120:144-9.

22 Hughes JR. An update on hardening: a qualitative review. Nicotine Tobacco Research. In Press. 